\title{
Prenatal hyperandrogenism induces alterations that affect liver lipid metabolism
}

\author{
Giselle Adriana Abruzzese', Maria Florencia Heber', Silvana Rocio Ferreira', \\ Leandro Martin Velez', Roxana Reynoso², Omar Pedro Pignataro ${ }^{3}$ and \\ Alicia Beatriz Motta1 \\ 1Laboratorio de Fisio-patología Ovárica, Centro de Estudios Farmacológicos y Botánicos (CEFYBO), \\ Consejo Nacional de Investigaciones Científicas y Técnicas (CONICET), Facultad de Medicina, Universidad \\ de Buenos Aires (UBA), Buenos Aires, Argentina \\ 2Laboratorio de Endocrinología, Departamento de Fisiología, Facultad de Medicina, Universidad de \\ Buenos Aires (UBA), Buenos Aires, Argentina \\ ${ }^{3}$ Laboratorio de Endocrinología Molecular y Transducción de Señales, Instituto de Biología y Medicina \\ Experimental, Consejo Nacional de Investigaciones Científicas y Técnicas (CONICET), Universidad de \\ Buenos Aires (UBA), Buenos Aires, Argentina
}

Correspondence should be addressed to G A Abruzzese Email giselleabruzzese@gmail.com

\begin{abstract}
Prenatal hyperandrogenism is hypothesized as one of the main factors contributing to the development of polycystic ovary syndrome (PCOS). PCOS patients have high risk of developing fatty liver and steatosis. This study aimed to evaluate the role of prenatal hyperandrogenism in liver lipid metabolism and fatty liver development. Pregnant rats were hyperandrogenized with testosterone. At pubertal age, the prenatally hyperandrogenized $(\mathrm{PH})$ female offspring displayed both ovulatory (PHov) and anovulatory (PHanov) phenotypes that mimic human PCOS features. We evaluated hepatic transferases, liver lipid content, the balance between lipogenesis and fatty acid oxidation pathway, oxidant/antioxidant balance and proinflammatory status. We also evaluated the general metabolic status through growth rate curve, basal glucose and insulin levels, glucose tolerance test, HOMA-IR index and serum lipid profile. Although neither $\mathrm{PH}$ group showed signs of liver lipid content, the lipogenesis and fatty oxidation pathways were altered. The PH groups also showed impaired oxidant/antioxidant balance, a decrease in the proinflammatory pathway (measured by prostaglandin E2 and cyclooxygenase-2 levels), decreased glucose tolerance, imbalance of circulating lipids and increased risk of metabolic syndrome. We conclude that prenatal hyperandrogenism generates both PHov and PHanov phenotypes with signs of liver alterations, imbalance in lipid metabolism and increased risk of developing metabolic syndrome. The anovulatory phenotype showed more alterations in liver lipogenesis and a more impaired balance of insulin and glucose metabolism, being more susceptible to the development of steatosis.
\end{abstract}

\section{Key Words}

- polycystic ovary syndrome

- fatty liver

- prenatal hyperandrogenism

- lipid metabolism
Journal of Endocrinology (2016) 230, 67-79 Printed in Great Britain
Published by Bioscientifica Ltd 


\section{Introduction}

Polycystic ovary syndrome (PCOS) is one of the most common endocrine and metabolic disorders that affects women in their reproductive age (Franks 2003) and its clinical manifestations often emerge during puberty (Rosenfield 2007, Yan et al. 2013). PCOS etiology remains controversial, and current theories emphasize on genetic and intrauterine origins coupled with environmental factors such as diet and altered lifestyle patterns (Franks 1995). It has been reported that prenatal androgen exposure is able to induce polycystic ovaries in rats (Demissie et al. 2008, Foecking et al. 2008), monkeys (Abbott et al. 2010) and sheep (Manikkam et al. 2006) and that fetal programming, mediated by prenatal hyperandrogenism, is related to hyperinsulinemia, dyslipidemia, insulin resistance (IR), cardiovascular disease and metabolic syndrome (Demissie et al. 2008, Amalfi et al. 2012, Heber et al. 2013). However, how fetal programming impacts on different tissues is unknown.

The liver is involved in lipid synthesis, transportation and storage, as well as in glucose and insulin metabolism (Paschos \& Paletas 2009), all key factors in PCOS pathogenesis (den Boer et al. 2004, Paschos \& Paletas 2009, Baranova et al. 2011, Vassilatou 2014). One of the most frequent hepatic affections, related to metabolic abnormalities, is nonalcoholic fatty liver disease (NAFLD), which affects $20-30 \%$ of the general population (Vassilatou 2014). NAFLD includes a clinicopathologic spectrum of conditions that encompass from simple steatosis (triglyceride (TG) accumulation in hepatocytes) to steatohepatitis with inflammation, fibrosis and even cirrhosis (Browning \& Horton 2004). NAFLD pathogenesis remains unknown and there are many hypotheses about its origin (Yasui et al. 2012, Lee et al. 2014). Currently, the most accepted model proposes a multiple and parallel hits hypothesis. Fatty acids and their metabolites are the lipotoxic agents involved in NAFLD development (Day \& James 1998, Lin et al. 2014), the increase in oxidative stress being one of the key factors in NAFLD pathogenesis (Madan et al. 2006, Lin et al. 2014).

In physiological conditions, in the liver, there is an equilibrium between the uptake and exportation of fatty acids (which in turn can be esterified or to be oxidized) (Browning \& Horton 2004, Kawano \& Cohen 2013). However, when the balance between lipolysis and lipogenesis is altered, or fatty acid influx to the liver is increased, lipid droplets could accumulate in the liver, leading to steatosis and even NAFLD (den Boer et al. 2004, Kawano \& Cohen 2013).
A common feature of NAFLD and PCOS is IR (Schwimmer et al. 2005, Gambarin-Gelwan et al. 2007). However, it remains controversial whether IR is the key cause in the development of NAFLD in women with PCOS (Liang \& Ward 2006, Gambarin-Gelwan et al. 2007). Since PCOS patients with hyperandrogenic phenotypes have a higher prevalence of developing NAFLD, it has been suggested that androgens could contribute to the development of the pathology (Vassilatou et al. 2010, Vassilatou 2014). We have previously demonstrated that the levels of androgen administered in pregnant rats are directly related to the PCOS-like phenotype displayed in the female offspring during the pubertal age (Amalfi et al. 2012) and that the fetal programming generated by androgens leads to metabolic alterations, particularly in lipid metabolism, which worsen through life (Heber et al. 2013). Based on the above, the aim of this study was to evaluate the effect of prenatal hyperandrogenism on the liver function and lipid metabolism.

\section{Materials and methods}

\section{Animals and treatments}

Virgin female rats of the Sprague Dawley strain were mated with fertile males of the same strain. Three females and one male were housed in each cage under controlled conditions of light $(12 \mathrm{~h}$ light: $12 \mathrm{~h}$ darkness cycle) and temperature $\left(23-25^{\circ} \mathrm{C}\right)$. Animals received food and water ad libitum. Day 1 of pregnancy was defined as the morning on which spermatozoa were observed in the vaginal fluid. As described previously (Demissie et al. 2008), pregnant rats $(N=15)$ received subcutaneous injections of $1 \mathrm{mg}$ free testosterone (T-1500; Sigma) dissolved in $100 \mu \mathrm{L}$ sesame oil from day 16 to day 19 of pregnancy. This hormonal paradigm mimics the fetal testosterone surge that is observed in male rats when the reproductive axis in the fetus is established. Another group $(N=15)$ received only $100 \mu \mathrm{L}$ sesame oil. The dose was selected based on previous findings of our laboratory (data not published) and other studies, which have shown that this dose leads to ovulatory and anovulatory phenotypes and that higher doses lead only to anovulatory phenotypes during the adult life and even to vaginal atresia (Wolf et al. 2002). Under the conditions of our animal facilities, spontaneous term labor occurs on day 22 of gestation. Female offspring were separated from males at 21 days of age and killed during pubertal age at 60 days of age. Those from hyperandrogenized mothers

Published by Bioscientifica Ltd. 
were the prenatally hyperandrogenized ( $\mathrm{PH})$ group and those from mothers injected with sesame oil were the control (Ctl) group. Animals were allowed free access to Purina rat chow (Cooperación SRL, Argentina) and water. All the procedures involving animals were conducted in accordance with the Animal Care and Use Committee of Consejo Nacional de Investigaciones Científicas y Tecnicas (CONICET) 1996, Argentina, and the study was approved by the Ethics Committee of the School of Medicine of University of Buenos Aires. To establish the phenotype diversity, the above procedures were independently repeated three times.

At 60 days of age, 75 female offspring from each group were anesthetized with carbon dioxide and killed by decapitation. Trunk blood was collected and serum was separated and kept at $-80^{\circ} \mathrm{C}$ for further studies. Ovaries and liver were extracted and conserved at $-80^{\circ} \mathrm{C}$ or fixed in $4 \%(\mathrm{v} / \mathrm{v})$ formaldehyde for histological studies. All animals were randomly assigned for each assay.

\section{Characterization of the prenatally hyperandrogenized murine model}

Serum testosterone was quantified from 15 offspring from each group by radioimmunoassay (RIA) as described previously (Amalfi et al. 2012). Serum estradiol levels were quantified by Cobase immunoassay analyzers using an electrochemiluminescence immunoassay (ECLIA) following the manufacturer's instructions. The intraand interassay coefficients of variation (CVs) were $7.3 \%$ and $13.2 \%$, respectively, for testosterone and 3.93 and $7.08 \%$, respectively for estradiol. The estrous cycle was determined by vaginal smears taken daily from 45 to 60 days of age in all the animals.

Regular ovulatory animals were those that showed smears displaying the four stages of the estrous cycle in the following order: proestrus, estrus, metaestrus, diestrus, with cycles of 4-6 days. Irregular ovulatory animals were both those that showed some smears displaying an estrous stage but further smears not following the progress of the cycle as described above, and those whose cycles lasted 7 days or more (PHov). Anovulatory animals were whose smears showed metaestrus, diestrus or a combination of both for four consecutive days, and were thus considered to be noncycling (PHanov) (Karim et al. 2003).

To evaluate ovarian histology, ten ovaries from each group were removed and immediately fixed in $4 \%(\mathrm{v} / \mathrm{v})$ formaldehyde and analyzed by two different investigators. Ovaries were embedded in paraffin wax and consecutively cut. To prevent counting the same follicle twice, $6 \mu \mathrm{m}$ step sections were mounted at $50 \mu \mathrm{m}$ intervals onto microscope slides. Then, slides were stained with hematoxylin and eosin (Woodruff et al. 1990).

\section{Hepatic enzymes}

Serum levels of alanine aminotransferase (ALT), aspartate aminotransferase (AST) and gamma-glutamyl transferase (GGT) were quantified by colorimetric enzymatic methods (Wiener Lab, Argentina) following the manufacturer's instructions. The chromophoric products were measured at $340 \mathrm{~nm}$ for ALT and AST and at $405 \mathrm{~nm}$ for GGT, all at $25^{\circ} \mathrm{C}$. The intra- and interassay $\mathrm{Cv}$ values were 3.02 and $5.63 \%$ for ALT, 4.4 and 4.9\% for AST, and 1.62 and 5\% for GGT.

\section{Liver lipid and TG content}

Fragments of hepatic tissue randomly selected from 15 female offspring from each group were fixed in formaldehyde $4 \%(\mathrm{v} / \mathrm{v})$, cut in cryostat and stained with SUDAN IV to visualize lipid droplets using hematoxylin as contrast stain. The intestine of tadpole was used as a positive control of the SUDAN IV technique (Regueira et al. 2016). To evaluate the TG content in the liver, 15 frozen samples of each group were saponified and TG content was quantified by comparing with a glycerol standard curve by using a commercial kit (Wiener Lab, Argentina), as described previously (Chow et al. 2011).

\section{Hepatic lipid metabolism}

The mRNA expression of acetyl-CoA carboxylase (ACC) 1 and 2 (Acaca and Acacb, respectively), fatty acid synthase (Fas), stearoyl-CoA desaturase ( $S c d 1)$, sterol regulatory element-binding protein1 (Srebp1), carbohydrate response element-binding protein (Chrebp), peroxisome proliferator-activated receptor alpha and gamma (Ppara and Ppar $\gamma)$ and PPAR $\gamma$ co-activator $1 \alpha(P g c 1 \alpha)$ was evaluated by real-time PCR analysis in 15 different samples from each group. Total mRNA from hepatic tissue was extracted using RNAzol RT (MRC gene, Molecular Research Center, Cincinnati, OH, USA) following the manufacturer's instructions. cDNA was synthesized from $500 \mathrm{ng}$ mRNA using random primers. real-time PCR analysis was performed from this cDNA by means of the real mix B124-100 (Biodynamics SRL, USA). The amplified products were quantified by fluorescence using the Rotor Gene 6000 Corbett and mRNA abundance was normalized to the
(C) 2016 Society for Endocrinology Printed in Great Britain
Published by Bioscientifica Ltd. 
Table 1 List of primers used in real-time PCR.

\begin{tabular}{|c|c|c|}
\hline \multicolumn{3}{|c|}{ Primers used in real-time PCR } \\
\hline Gene & Primers sequences & $\begin{array}{l}\text { Temperature of } \\
\text { melting }\left({ }^{\circ} \mathrm{C}\right)\end{array}$ \\
\hline Ppary F & 5'-TTTTCAAGGGTGCCAGTTTC-3' & 60 \\
\hline Ppary R & 5'-GAGGCCAGCATGGTGTAGAT-3' & \\
\hline Srebp F & 5'-TAACCTGGCTGAGTGTGCAG-3' & 60 \\
\hline Srebp R & 5'-ATCCACGAAGAAACGGTGAC-3' & \\
\hline Chrebp F & 5'-GGTTGTCCCCAAAGCAGAGA-3' & 62 \\
\hline Chrebp R & 5'-TTGTTGTCTACACGACCCCG-3' & \\
\hline Acaca $\mathrm{F}$ & 5'-CCAGACCCTTTCTTCAGCAG-3' & 62 \\
\hline Acaca $\mathrm{R}$ & 5'-AGGACCGATGTGATGTTGCT-3' & \\
\hline Acacb F & 5'-CAAAGCCTCTGAAGGTGGAG-3' & 62 \\
\hline Acacb R & 5'-CTCGTCCAAACAGGGACACT-3' & \\
\hline Fas $\mathrm{F}$ & $5^{\prime}$-TCGAGACACATCGTTTGAGC-3' & 62 \\
\hline Fas $\mathrm{R}$ & 5'-CCCAGAGGGTGGTTGTTAGA-3' & \\
\hline $\mathrm{Scd} 1 \mathrm{~F}$ & 5'-GCTTCCAGATCCTCCCTACC-3' & 62 \\
\hline Scd1 R & 5'-CAACAACCAACCCTCTCGTT-3' & \\
\hline Ppar $\alpha \mathrm{F}$ & 5'-TCACACGATGCAATCCGTTT- $3^{\prime}$ & 60 \\
\hline Ppara R & 5'-GGCCTTGACCTTGTTCATGT-3' & \\
\hline $\operatorname{Pgc1} \alpha \mathrm{F}$ & 5'-AATGCAGCGGTCTTAGCACT-3' & 60 \\
\hline Pgc1 $\alpha \mathrm{R}$ & 5'-GTGTGAGGAGGGTCATCGTT-3' & \\
\hline$L 32 \mathrm{~F}$ & 5'-TGGTCCACAATGTCAAGG-3' & 58 \\
\hline L32 R & 5'-CAAAACAGGCACACAAGC-3' & \\
\hline
\end{tabular}

$F$, forward sequence; $R$, reverse sequence. 60s ribosomal protein L32 (L32) amount. L32 was validated as a reference gene because the variance between treatments did not differ. Results are expressed as arbitrary units. The primers are given in Table 1.

\section{Liver oxidant/antioxidant balance}

The oxidant-antioxidant balance in liver tissue was evaluated as the lipid peroxidation index and the content of the antioxidant glutathione (GSH) in 15 samples of each group. The amount of malondialdehyde formed from the breakdown of polyunsaturated fatty acids is taken as an index of the peroxidation reaction. The method used in this study was as that described previously (Amalfi et al. 2012, Heber et al. 2013). The reduced form of GSH, which comprises the bulk of cellular protein sulfhydryl groups, was quantified as described previously (Amalfi et al. 2012, Heber et al. 2013).

\section{Liver inflammatory status}

The inflammatory status in liver tissue was measured by evaluating the levels of prostaglandin E (PGE) and cyclooxygenase-2 (COX2), the limiting enzyme of its synthesis. PGE was determined by RIA as reported
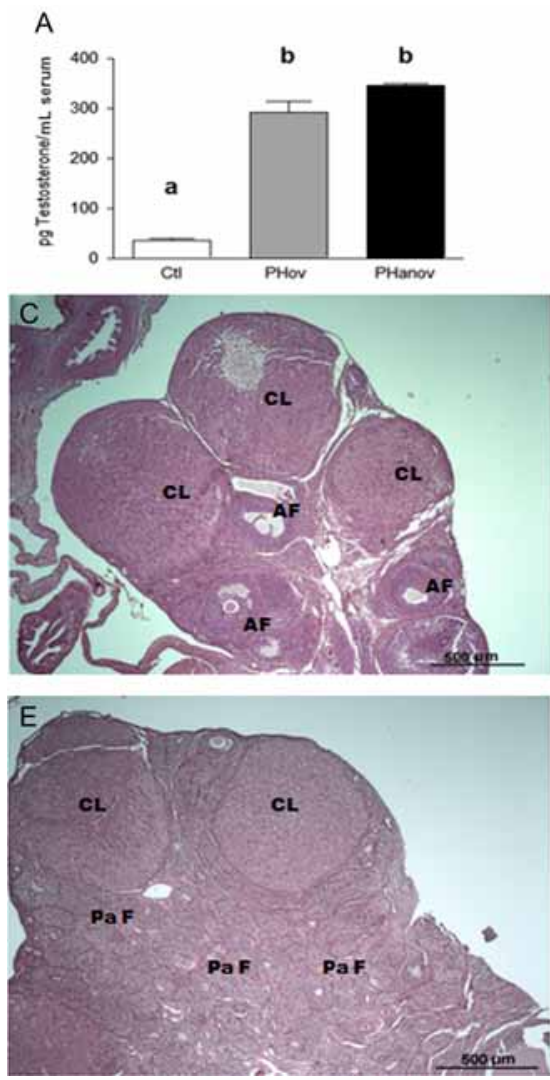
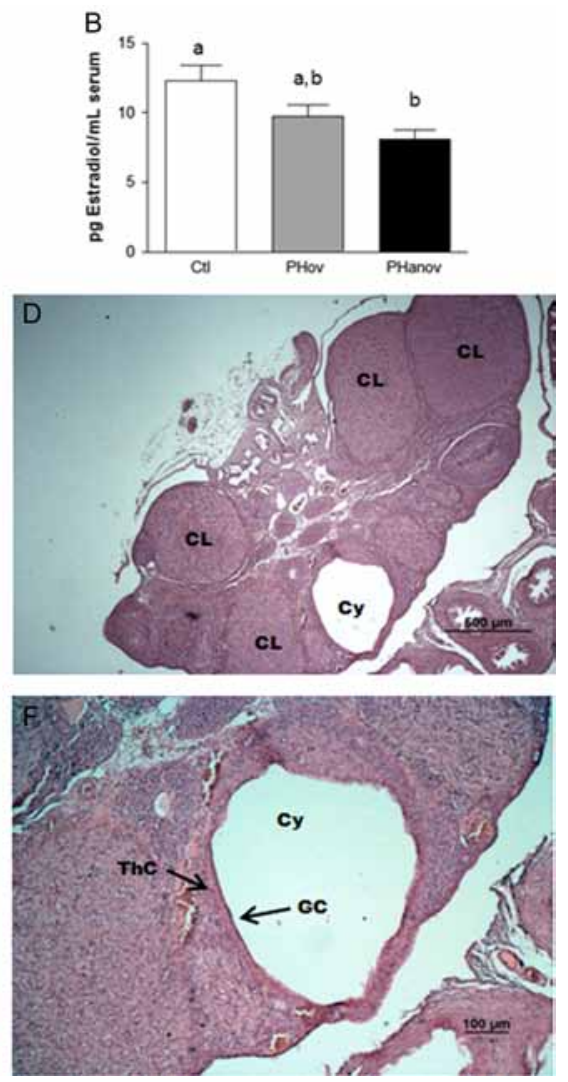

Figure 1

Prenatally hyperandrogenized murine model. Prenatal hyperandrogenism in female offspring of control (Ctl) and prenatally hyperandrogenized $(\mathrm{PH})$ groups. (A) Serum testosterone levels. Each column represents the mean \pm s.E.M. from 15 different animals per group, $a$ vs $b P<0.01$ by ANOVA test. (B) Serum estradiol levels. Each column represents the mean \pm s.E.M. from 15 different animals per group, $a$ vs $b$ $P<0.05$ by ANOVA test. (C) A representative ovarian tissue section from the $\mathrm{Ctl}$ group (40x). (D) A representative ovarian tissue section from the PHov group (40x). (E) A representative ovarian tissue section from the PHanov group (40x). (F) Detail of a representative ovarian cyst from the PH groups (100x). Corpus luteum (CL), antral follicle (AF), cyst (Cy), granulosa cells (GC), theca cells (ThC) and preantral follicles (PaF). A full colour version of this figure is available at http://dx.doi.org/10.1530/JOE-15-0471. http://joe.endocrinology-journals.org DOI: $10.1530 / \mathrm{JOE}-15-0471$
(C) 2016 Society for Endocrinology Printed in Great Britain
Published by Bioscientifica Ltd 
previously (Motta et al. 1999). COX2 was measured by the western blotting technique, using $200 \mathrm{mg}$ liver tissue from 10 independent samples per group, as described previously (Amalfi et al. 2012).

\section{General metabolism imbalance}

The body weight of all the animals of all the groups was determined at 21, 28, 38, 45 and 60 days of age. Basal insulin levels were measured by an ELISA kit, following the manufacturer's instructions (Abcam Insulin Human ELISA Kit), and basal glucose levels were quantified by colorimetric enzymatic methods (Wiener Lab, Argentina) ( $N=10$ per group). The intra- and interassay $\mathrm{Cv}$ values were 10 and 12\%, respectively, for insulin, and 1.39 and $1.92 \%$, respectively, for glucose.

The glucose tolerance test (IPGTT) was performed in separate groups of 10 female offspring from each group, as described previously (Demissie et al. 2008,
Amalfi et al. 2012). The homeostatic model assessment for IR (HOMA-IR) was determined (Yan et al. 2013). The circulating lipid profile was evaluated as described previously and the TG/HDL cholesterol ratio was taken as a marker of metabolic syndrome risk (Heber et al. 2013).

\section{Statistical analysis}

Statistical analyses were carried out using Instant program (GraphPad Software). ANOVA with post hoc Tukey test was used to compare the three treatments. Statistical significance was considered as $P<0.05$.

\section{Results}

\section{Characterization of the prenatally hyperandrogenized murine model}

The PHov and PHanov groups showed higher serum testosterone levels than the control group, but only
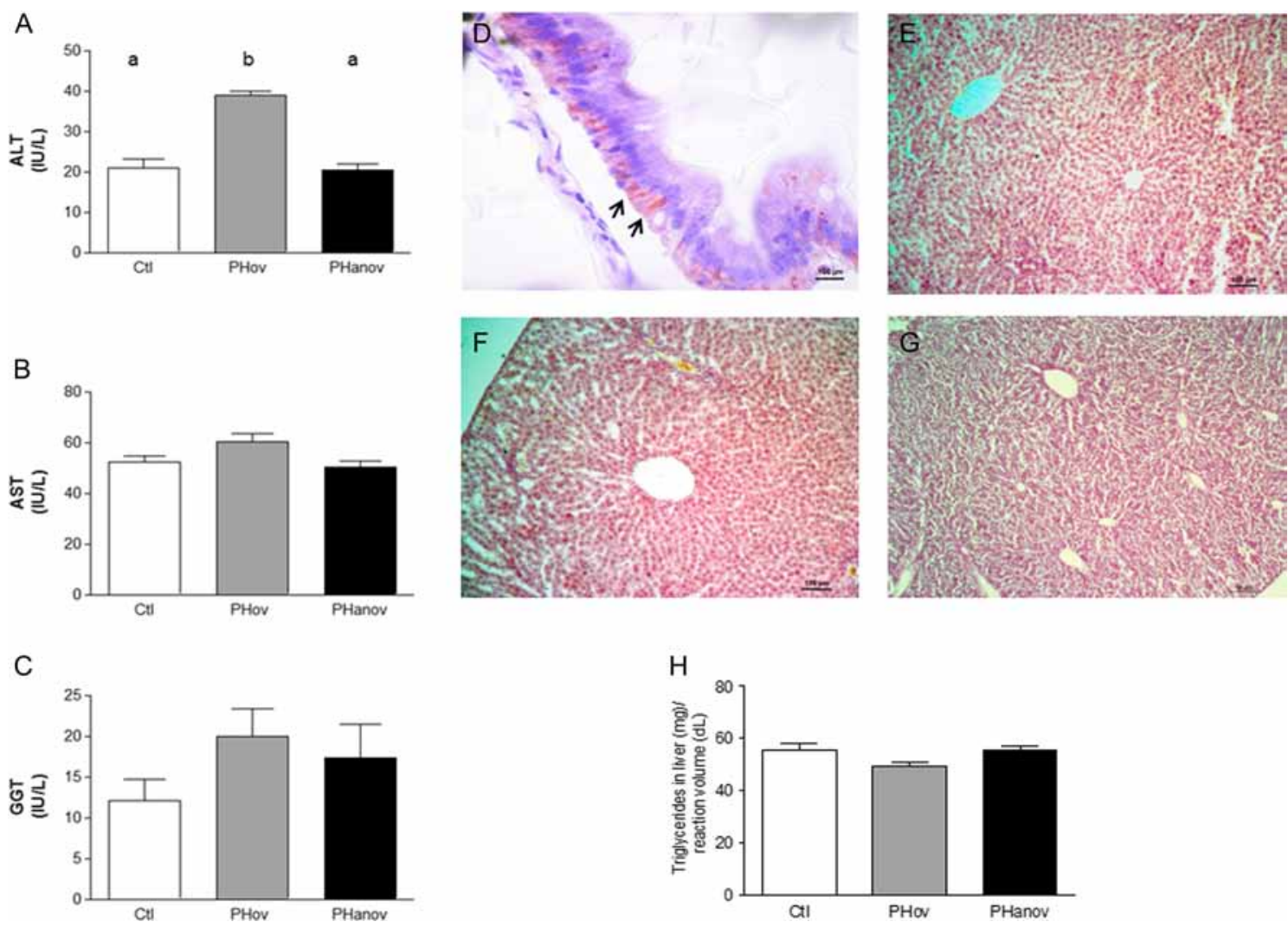

\section{Figure 2}

Effects of prenatal hyperandrogenism on liver transaminase levels and lipid content. (A) Serum levels of ALT and (B) AST. (C) GGT. Each column represents the mean \pm S.E.M. of control $(\mathrm{Ctl})$ and prenatally hyperandrogenized ( $\mathrm{PH}$ ) groups; a vs $\mathrm{b} P<0.05$, by ANOVA test. Liver lipid content was quantified by SUDAN IV staining. (D) The cytoplasmic lipid droplets are shown in red, as shown in the positive control of the technique (arrows). Each photo shows the detail (100x) of a representative staining of the Ctl group (E) and PHov (F) and PHanov groups (G). There was no evidence of cytoplasmic lipid accumulation. (H) TG content in the liver. No significant differences were found between the $\mathrm{Ctl}$ and $\mathrm{PH}$ groups $(P<0.05$, by $\mathrm{ANOVA}$ test). A full colour version of this figure is available at http://dx.doi.org/10.1530/JOE-15-0471.

http://joe.endocrinology-journals.org DOI: 10.1530/JOE-15-0471
C 2016 Society for Endocrinology Printed in Great Britain
Published by Bioscientifica Ltd 
PHanov animals displayed lower estradiol levels than the control (Fig. $1 \mathrm{~A}$ and $\mathrm{B}, P<0.01$ ). Figure $1 \mathrm{C}$ shows a representative ovarian tissue section from the control group. The general appearance of the tissue resembled normal histology: a central medulla consisting mainly of fibromuscular stroma and corpora lutea and antral follicles located in the peripheral cortex. Histological examination of ovaries from the PHov and PHanov groups (Fig. 1C and D) revealed the presence of corpora lutea, cysts and an excess of small antral follicles. In addition, in PHanov animals, the ovary was disorganized as compared with the control group and small follicles could be seen invading the central medulla. The detail in Fig. 1E shows that cysts present a layer of theca cells and a thin compacted formation of granulosa cells.

Regarding the estrous cycle, in the three independent repetitions of the animal procedure, always $100 \%$ of the control rats showed a regular estrous cycle. Within the PH group, 43-51\% showed irregular estrous cycles and were considered as PHov, whereas $27-39 \%$ presented anovulatory cycles and were considered PHanov. Testosterone did not affect the age of vaginal opening.

\section{Prenatal hyperandrogenism and hepatic alterations}

ALT levels were increased in the PHov group (Fig. 2A, $P<0.01)$. Neither AST nor GGT levels were affected in the PHov or PHanov groups as compared with the control group (Fig. 2B and $\mathrm{C}$ respectively, $P>0.05$ ).

As compared with the positive control of the SUDAN IV technique (Fig. 2D, arrows), neither the control group (Fig. 2E) nor the PHov or PHanov phenotypes (Fig. 2F and G) showed hepatic lipid droplets. In addition, no differences were found in the hepatic TG content between groups (Fig. $2 \mathrm{H}, P>0.05$ ).
A

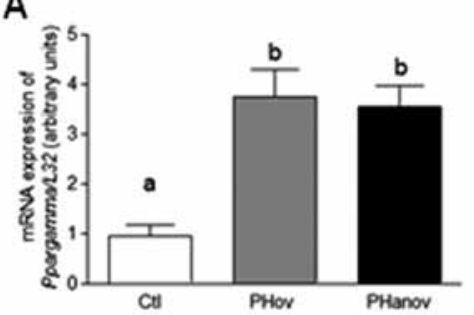

D

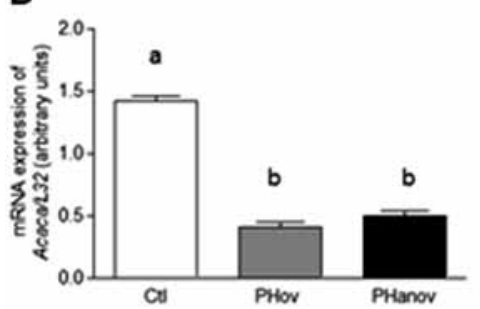

G

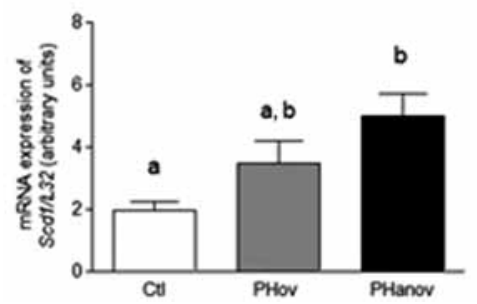

B

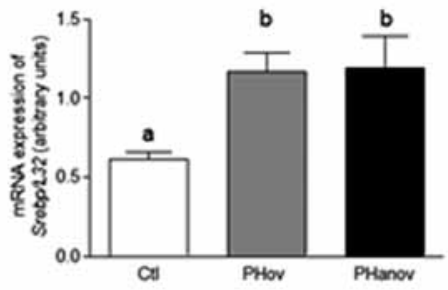

E

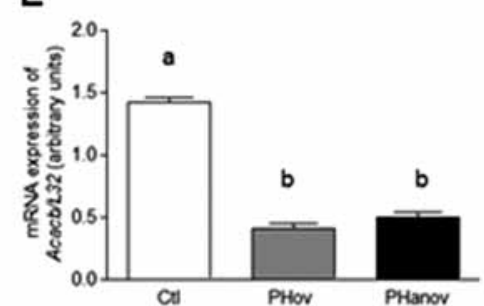

H

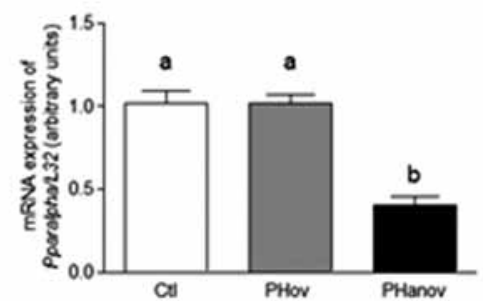

C

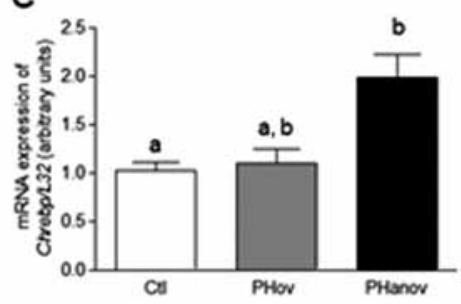

$\mathbf{F}$

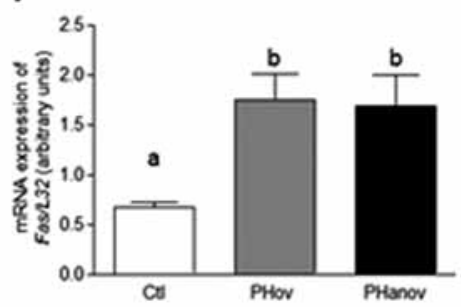

1

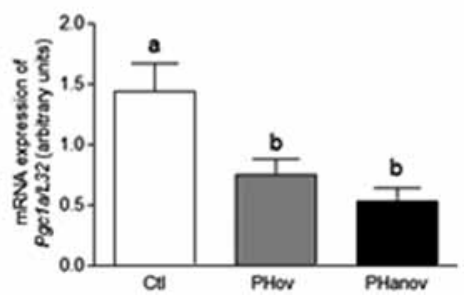

Figure 3

Effects of prenatal hyperandrogenism on liver lipid metabolism. The graphs correspond to the mRNA abundance of the gene of interest relative to $L 32$ mRNA levels of control ( $\mathrm{Ctl}$ ) and prenatally hyperandrogenized $(\mathrm{PH})$ groups. $L 32$ was validated as a reference gene using Cts (cycle threshold) $($ Control $=21.76+0.24 ; \mathrm{PHov}=21.36+0.30 ; \mathrm{PHanov}=21.70+0.34 ; P=0.67)(\mathrm{A})$ Gene expression of $P p a r \gamma(\mathrm{a}$ vs b $P<0.01),(\mathrm{B}) \mathrm{Srebp}(\mathrm{a}$ vs b $P<0.05)$ (C) Chrebp (a vs b $P<0.05$ ), (D) Acaca (a vs b $P<0.01$ ), (E) Acacb (a vs b $P<0.01$ ), (F) Fas (a vs b $P<0.01$ ), (G) $S c d 1$ (a vs b $P<0.05$ ), (H) $P p a r \alpha(a$ vs b $P<0.01$ ) and (I) Pgc1 $\alpha$ (a vs b $P<0.01$ ). Each column represents the mean \pm s.E.M. Statistical analyses were made by ANOVA test. 

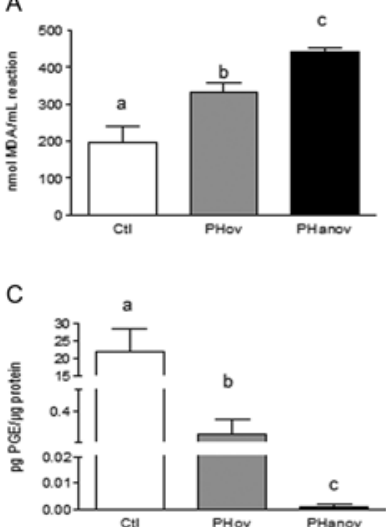

B
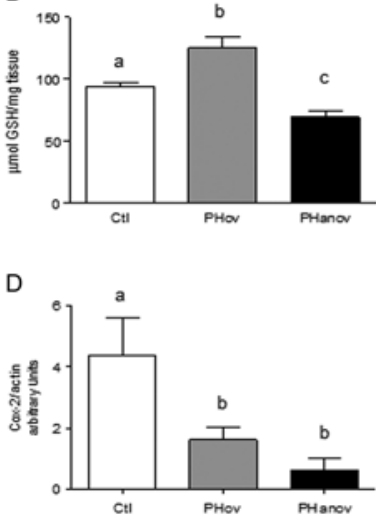

Figure 4

Effects of prenatal hyperandrogenism on liver oxidant/antioxidant balance and proinflammatory status. The oxidant-antioxidant balance in liver tissue was evaluated by measuring the lipid peroxidation index $(A)$ and the content of the antioxidant glutathione (B). Each column represents the mean \pm S.E.M. Different letters mean statistical significant differences $(a \neq b \neq c, P<0.05$ in both cases, by ANOVA test). (C) Liver PGE content was measured to evaluate the pro-inflammatory status $(a \neq b \neq c$, $P<0.01$ by ANOVA). (D) To evaluate whether PGE levels were influenced by the limiting enzyme of its synthesis, COX2 was measured, a vs $b P<0.05$, by ANOVA test. Each column represents the mean \pm S.E.M.
Regarding the transcription factors that are mediators of lipogenesis, we found that Ppary and Srebp mRNA levels were higher in both PH groups than in the control group (Fig. 3A and $\mathrm{B}, P<0.05)$, whereas Chrebp levels were only altered in the PHanov animals (Fig. 3C, $P<0.05$ ). Regarding the enzymes involved in lipogenesis, we found that the mRNA levels of the genes encoding both isoforms of acetyl-CoA carboxylase (Acaca and Acacb) were decreased in both PH groups (Fig. 3D and $\mathrm{E}, P<0.05)$. Fas mRNA levels were increased in the $\mathrm{PH}$ groups (Fig. 3F, $P<0.05$ ), whereas $S c d 1$ mRNA levels were only impaired in PHanov animals (Fig. 3G, $P<0.05$ ).

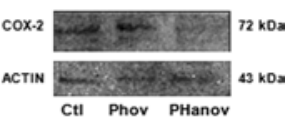

Regarding fatty acid oxidation pathways, we found that Ppara mRNA levels showed no differences between the control and PHov groups but were decreased in PHanov (Fig. 3H, $P<0.01$ ), and that $P g c 1 \alpha$ levels were lower in both $\mathrm{PH}$ animals than in controls (Fig. 3I, $P<0.01)$.

L32 was validated as a reference gene, obtaining no statistical difference in the stability between treatments measured by the $\mathrm{Ct}$ (threshold cycle) $($ control $=21.76+0.24 ; \quad$ PHov $=21.36+0.30 ;$ PHanov $=21.70+0.34 ; P=0.67)$.

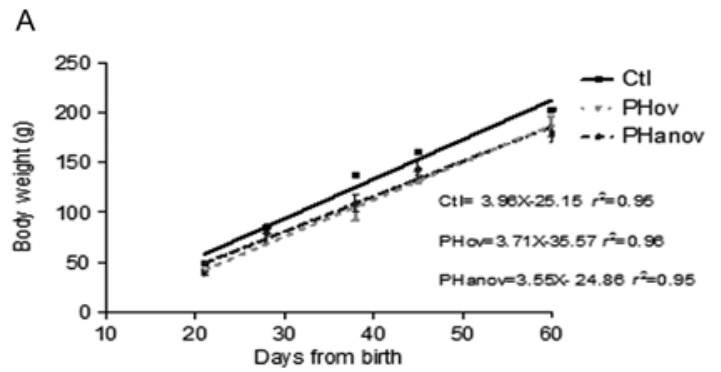

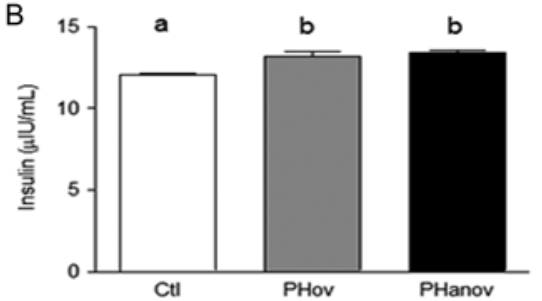
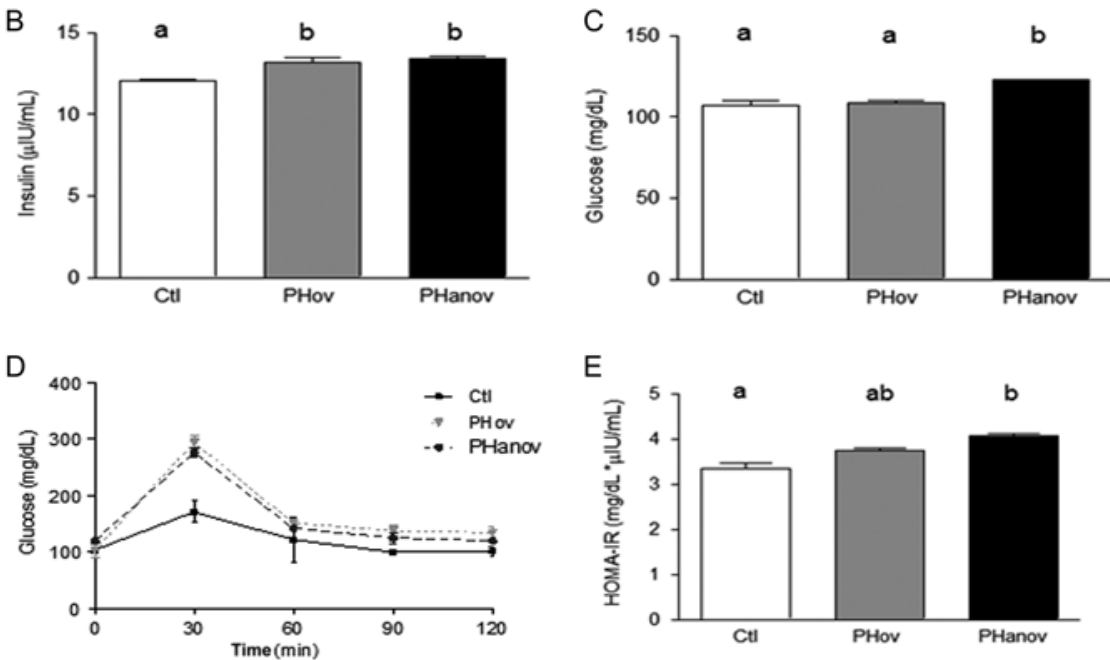

$\mathrm{E}$

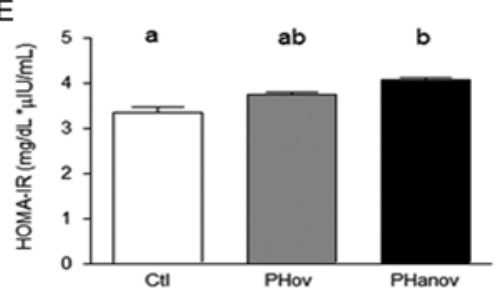

Figure 5

Prenatal hyperandrogenism and metabolic derangements. Metabolic features evaluated in female offspring of control (CtI) and prenatally hyperandrogenized $(\mathrm{PH})$ groups. (A) The curve represents the mean growth rates of the $\mathrm{Ctl}$ and $\mathrm{PH}$ groups. Differences between growth rates were not significant $(P<0.05$, by ANOVA test). (B) Basal insulin levels, a vs b $P<0.05$. (C) Basal glucose levels; a vs $b P<0.05$. (D) Blood samples followed by intraperitoneal injection of $2 \mathrm{~g}$ dextrose/kg body weight were collected at 0,30 60,90 , and 120 min post injection for IPGTT. (E) HOMA-IR index; a vs b $P<0.05$. Values are mean \pm s.E.M. by ANOVA test. 
A

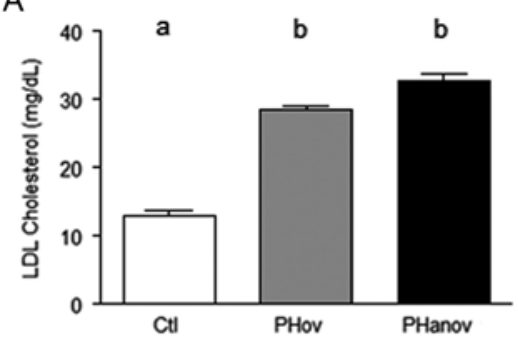

C

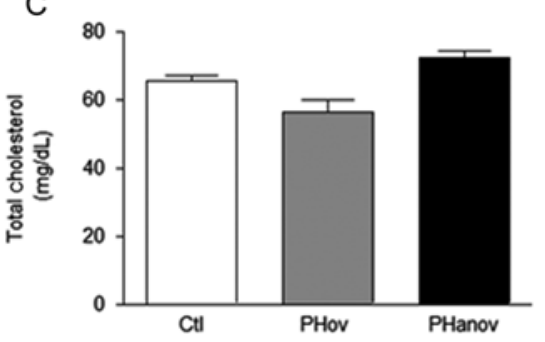

B

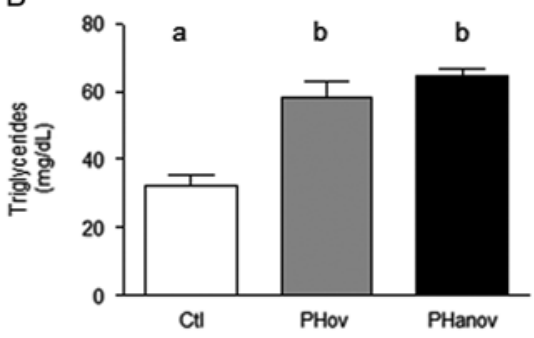

D

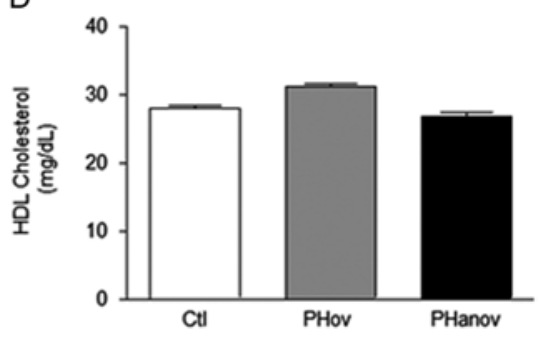

Figure 6

Effect of prenatal hyperandrogenism on the circulating lipid profile. (A) Serum levels of low-density lipoprotein cholesterol (LDLcholesterol), (B) triglycerides, (C) total cholesterol and (D) high-density lipoprotein cholesterol (HDL-cholesterol). Each column represents the mean \pm S.E.M. of control (Ctl) and prenatally hyperandrogenized $(\mathrm{PH})$ groups; a vs $\mathrm{b} P<0.01$ panel A; $P<0.05$ panel B. Data were analyzed by ANOVA test.
The lipid peroxidation index was higher in the $\mathrm{PH}$ groups than in the control (Fig. 4A, $P<0.05$ ). GSH levels were altered in both $\mathrm{PH}$ groups as compared with the control. GSH levels were increased in the PHov groups and decreased in the PHanov group (Fig. 4B, $P<0.01)$.

Both the levels of PGE and the protein expression of COX2 were lower in the $\mathrm{PH}$ groups than in the control group. In addition, the PGE levels were lower in the PHanov group than in the PHov animals (Fig. $4 \mathrm{C}$ and D, $P<0.01)$.

\section{Prenatal hyperandrogenism and metabolic derangements}

Prenatal hyperandrogenism did not affect the body weight from prepubertal to pubertal age (Fig. 5A, $P=0.41$ ). Insulin levels were increased in both $\mathrm{PH}$ groups as respect to controls (Fig. 5B, $P<0.05$ ), and basal glucose levels were impaired in the PHanov group (Fig. 5C, $P<0.05$ ). The IPGTT showed that prenatal hyperandrogenism induced increased levels of circulating glucose (Fig. 5D), represented by the area under the curve of glucose concentration

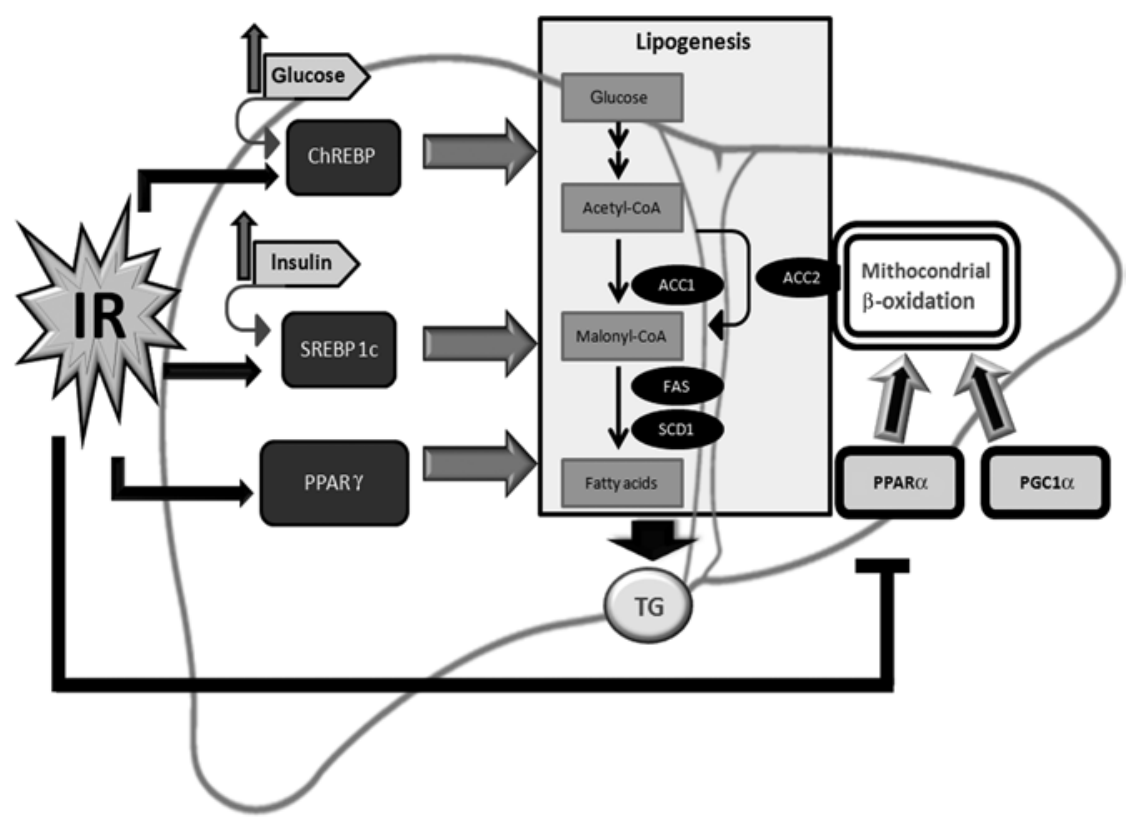

Figure 7

Mediators of hepatic lipogenesis and $\beta$-oxidation. SREBP, ChREBP and PPAR $\gamma$ are transcription factors involved in the regulation of hepatic lipogenesis. Insulin and glucose modulate SREBP and ChREBP, respectively. These transcription factors and PPAR $\gamma$ positively regulate de novo lipogenesis by modulating the expression of the enzymes involved in this pathway. On the other hand, PPAR $\alpha$ and PGC1 $\alpha$ are positive regulators of genes involved in fatty acid oxidation. A balance between these processes is needed to avoid hepatic liver accumulation leading to steatosis. Insulin resistance is associated with an increase in lipogenesis due to an upregulation of ChREBP, SREBP1c and PPAR $\gamma$ and a decrease in fatty acid oxidation due to a negative regulation on PPAR $\alpha$. 
$($ control $=14873.0 \pm 119.7 ; \quad$ PHov $=21045.0 \pm 164.0 ;$ PHanov $=2090.0 \pm 156.6$ in arbitrary units, control vs PHov $P<0.01$; control vs PHanov $P<0.05$; PHov vs PHanov $P>0.05)$. The HOMA-IR index was increased in the PHanov group as compared with controls (Fig. 5E, $P<0.05)$.

Both $\mathrm{PH}$ groups showed an altered circulating lipid profile, displaying higher levels of circulating lowdensity lipoprotein cholesterol (LDL) (Fig. 6A, $P<0.05$ ) and TG than the control group (Fig. 6B, $P<0.01$ ). No significant differences were found in the levels of total cholesterol or high-density lipoprotein (HDL) cholesterol (Fig. 6C and D, P>0.05). The TG/HDL cholesterol ratio, as a marker of metabolic syndrome risk, was higher in both $\mathrm{PH}$ groups than in the control group (control $=1.13 \pm 0.34$; PHov $=2.42 \pm 0.24 ;$ PHanov $=2.65 \pm 0.39, P<0.05 ;$ PHov vs control and PHanov vs control, $P>0.05$ PHov vs PHanov).

\section{Discussion}

The developmental origins of PCOS are controversial. Some authors have reported that an altered in utero environment could be responsible for metabolic diseases and PCOS features development in different species (Abbott et al. 2005, Demissie et al. 2008, Hogg et al. 2011), whereas others propose PCOS as a multiplicity of etiologies and not a simple mechanism and emphasize genotype features (Gluckman \& Hanson 2004, Franks \& Berga 2012). It is known that both the embryo development stages and early postnatal life period are crucial to condition adult health life. Thus, currently used PCOS animal models focus on these critical development time windows (Manikkam et al. 2006, Demissie et al. 2008, Abbott et al. 2010, Amalfi et al. 2012, Jang et al. 2015). Furthermore, the metabolic and endocrine alterations found in the prenatal models lead to several long-term effects, thus highlighting the importance of the in utero environment.

In the present study, we reproduced a murine model which displayed PCOS features leading to two phenotypes: with both hyperandrogenism and ovarian alterations, such as an increase in the number of preantral follicles and the formation of cysts. Nearly $50 \%$ of the cases of the PH group presented irregular ovulatory estrous cycles, whereas around $40 \%$ of the cases in $\mathrm{PH}$ group presented the anovulatory phenotype.

Ovaries from PCOS women are known to contain an increased number of small follicles that have an excessive early growth but with follicular arrest, thus preventing the selection and further maturation of a dominant follicle. These data are in accordance with our results showing that androgens play a role in follicle recruitment (Jonard \& Dewailly 2004).

We found that $\mathrm{PH}$ rats showed incipient liver damage. These data are in agreement with previous reports that suggest that the intrauterine environment plays an important role in the development of both NAFLD and PCOS during postnatal life (Baranova et al. 2013, Brumbaugh \& Friedman 2014).

Contrary to other reports (Demissie et al. 2008, Hogg et al. 2011), we found no lipid accumulation in the liver. This difference could be due to the higher doses of androgens used in those reports and is in agreement with our previous findings where higher doses of androgens induced a more severe PCOS-like phenotype as well as worse endocrine and metabolic disturbances (Amalfi et al. 2012). To deepen the study of lipid metabolism in the liver, we evaluated the status of the de novo lipogenesis pathway and $\beta$-fatty acid oxidation mediators (Fig. 7). To assess the lipogenic pathway, we evaluated the role of three transcription factors involved in the regulation of de novo lipogenesis. Two of them, SREBP and CHREBP, are regulated by insulin and glucose levels, respectively, and both regulate the expression of genes encoding lipogenic enzymes (Browning \& Horton 2004, Strable \& Ntambi 2010). Our results showed that the $\mathrm{PH}$ groups presented high levels of Srebp, consistent with the high levels of serum insulin found in $\mathrm{PH}$ animals. Moreover, Chrebp was impaired in the PHanov group, showing a correlation with basal glucose levels in those animals. These data are in accordance with that described by other authors showing that in the hyperinsulinemic and even more in the IR states, SREBP1-c transcription is stimulated and could lead to de novo fatty acid synthesis (Browning \& Horton 2004, Strable \& Ntambi 2010). The third transcription factor studied, also involved in the regulation of lipogenesis, was PPAR $\gamma$. It has been shown that in animal models of IR, PPAR $\gamma$ levels are increased, promoting lipid storage (Ables 2012, Kawano \& Cohen 2013). In agreement with these data, our results showed increased Pppary levels in the PH groups, thus highlighting the relationship between liver lipid metabolism and glucose and insulin metabolism. Although only the PHanov phenotype presented signs of IR, by the HOMA-IR index, both PH groups showed increased insulin levels and decreased glucose tolerance by the IPGGT test.

In addition to an altered expression of the transcription factors modulating lipogenic genes, we found alterations in the mRNA levels of the genes

Published by Bioscientifica Ltd 
encoding FAS and SCD1, both enzymes involved in lipogenesis. Both PH groups showed increased levels of Fas, but only the PHanov group showed altered levels of Scd1, the enzyme leading to monounsaturated fatty acids. Thus, although the lipogenic pathway was altered in both PH groups, the PHanov showed a deeper dysregulation of the lipogenesis system.

The first limiting factor in lipogenesis is the synthesis of malonyl-CoA, which is synthesized by ACC, which is present in both isoforms encoded by the Acaca and Acacb genes. Our results surprisingly showed that both mRNA levels were decreased in the $\mathrm{PH}$ groups, independently of the increased levels of Srebp, Chrebp and Ppary. Malonyl$\mathrm{COA}$ is an indirect inhibitor of fatty acid oxidation (Browning \& Horton 2004), and it has been described that when one of the ACC isoforms is reduced, fatty acid oxidation results increased. These findings suggest that the reduction in Acaca and Acacb expression could be due to the effect of other regulatory mechanisms (independently of Ppary, Srebp and Chrebp action), which may be preventing lipid accumulation by decreasing malonylCoA synthesis (Savage et al. 2006, Strable \& Ntambi 2010), thus favoring fatty acid oxidation.

Our results are in accordance with other studies (Mao et al. 2006, Strable \& Ntambi 2010) that show that Acaca levels are independent of the expression of the genes involved in fatty acid synthesis. In fact, the knockout of Acaca shows increased levels of several genes that encode proteins involved in lipogenesis but without hepatic lipid accumulation (Mao et al. 2006, Strable \& Ntambi 2010). These data demonstrate that Acaca could be playing a protective role in the development of hepatic steatosis.

In addition to the alterations found in the lipogenesis pathways, we found derangements in fatty acid oxidation (Fig. 7). By having opposite functions, Ppara and Ppary regulate fat metabolism and while Ppary promotes lipid storage and Ppar $\alpha$ promotes lipid utilization (Ables 2012, Kawano \& Cohen 2013, Souza-Mello 2015). In the present study, prenatal hyperandrogenization decreased Ppara levels in the liver of PHanov animals, suggesting that this group could be more sensitive to hepatic steatosis. We also found that the levels of the PPARs coactivator, $P g c 1 \alpha$, a key regulator of lipid metabolism, were decreased in both PH groups as compared with the control group. In fact, PGC1 $\alpha$ not only acts as a regulator of PPARs but also promotes oxidation of fatty acids by binding to specific transcription factors, modulates mitochondrial functions and controls glucose homeostasis (Liang \& Ward 2006, Fernandez-Marcos \& Auwerx 2011). Taken together, our data suggest that dysregulation of lipogenesis and fatty acid oxidation could lead to the long-term development of hepatic damage, deepened by decreased insulin sensitivity.

Oxidative stress and the proinflammatory process are also involved in the pathogenesis of hepatic damage. Oxidative stress is involved in the regulation of very lowdensity lipoprotein (VLDL) production and its excretion by the liver (Pan et al. 2004). Moreover, the addition of GSH to rat hepatoma cells reverses steatosis and decreases lipid peroxidation levels (Pan et al. 2004). In the liver, GSH levels correlate with high levels of circulating LDL cholesterol, which reinforces the association between the oxidative balance and lipid metabolism (Lin et al. 2014). In agreement with these findings, in this study we found that GSH compensated the damage caused by lipid peroxidation in the PHov group but not in the PHanov group. We suggest that in the PHov group, GSH could be modulating VLDL secretion from the liver to the circulation, as manifested by the increased levels of serum LDL observed, and thus preventing the accumulation of VLDL, as evidenced by the lack of accumulation of lipid droplets.

As mentioned before, the proinflammatory process is involved in the development of NAFLD (Day \& James 1998) and prostaglandins, and COX2 play a role in lipid metabolism and lipid accumulation in the liver (Yu et al. 2006, Hsieh et al. 2009, Ii et al. 2009). Increased levels of PGE correlate with TG accumulation in the liver (Hsieh et al. 2009, Ii et al. 2009, Henkel et al. 2012). In agreement with these data, we found that decreased levels of PGE and COX2 in the PH groups evidenced an alteration in the proinflammatory mediators that could be preventing liver fat accumulation. In fact, the decrease in the inflammatory pathway in the PH groups correlated with a lack of increase in TG content. These results contribute to the explanation of the absence of lipid droplets in the PHanov group. Although the liver PPAR system was altered and lipogenesis was favored, there was a systemic manifestation of these consequences seen by an altered circulating lipid profile. Thus, a depletion of the proinflammatory mediators could be acting as a compensatory system.

Hepatic transaminases have been described as markers of liver function and damage (Vassilatou 2014). Although ALT is one of the hepatic enzymes mostly used as a marker to detect hepatic injury, several studies have shown other causes for its increase, including growth spurs and looming diabetes (Burgert et al. 2006, Vassilatou 2014). 
Despite these findings, it remains controversial whether ALT is a good marker for liver function because some individuals have NAFLD but normal ALT levels and vice versa (Kim et al. 2008). It has been recommended that increased levels of these enzymes in blood may only be used to detect the inflammation that occurs in the liver due to injury or damage. Unexpectedly, we found increased levels of ALT only in PHov animals. Thus, as the PHanov group presented a great depletion of the proinflammatory status, then ALT serum levels would not be affected in these animals (Kerner et al. 2005, Burgert et al. 2006, Yamada et al. 2006).

It should be pointed out that the incidence of NAFLD and liver fat accumulation are associated with increasing age and body weight (Michaliszyn et al. 2013, Park et al. 2014). In this study, we found no alterations in body weight or fatty liver presence related to the decreased liver inflammation. However, studies are being carried out in adult rats, as we found that derangements in the metabolic pathway of lipogenesis could worsen through life (Heber et al. 2013).

Women with the more severe PCOS phenotype show increased prevalence of NAFLD (Jones et al. 2012). Herein, we found that the PHanov group was the most affected, displaying decreased expression of Pgc1 $\alpha$ and Ppar $\alpha$ and overexpression of Ppary, Srebp and Chrebp, thus being more susceptible to presenting signs of hepatic steatosis and damage in the long term (Browning \& Horton 2004, Estall et al. 2009).

Our data are in accordance to the multiple hits hypothesis (Day \& James 1998, Lin et al. 2014) to explain the origins of NAFLD. This involves IR, fatty acid signaling impairment, oxidative stress and inflammation as contributing factors to NAFLD development. As we found no lipid accumulation but alterations in the processes described, steatosis may be a consequence of hepatic signaling derangements and systemic metabolic detriment. We do not discard that the hepatic alterations found could be due to an increased testosterone/estradiol ratio, worsened in the PHanov group.

In summary, our data show for the first time that both ovulatory and anovulatory phenotypes that mimics PCOS features present at pubertal age, signs of incipient liver injury and an imbalance of the fatty acid metabolism mediated by the PPAR system, SREBP and CHREBP, as well as an imbalance of the lipogenic enzymes but without development of NAFLD. These derangements are related to systemic effects, dyslipidemia and decreased glucose tolerance.

\section{Declaration of interest}

The authors declare that there is no conflict of interest that could be perceived as prejudicing the impartiality of the research reported.

\section{Funding}

This study was supported by grants from Agencia Nacional de Promoción Científica y Tecnológica (ANPCyT) (Grant PICT 577/2012 and PICT 689/2013), Argentina. G A A, M F H and L M V are supported by a doctoral fellowship awarded by CONICET, and S R F by ANPCYT. O P P and A B M. are PhD from CONICET.

\section{Author contribution statement}

A M B, G A A and M F H conceived and designed the experiments. G A A, M $\mathrm{F} \mathrm{H}, \mathrm{S} R \mathrm{~F}, \mathrm{~L} M \mathrm{~V}, \mathrm{R} R$ and O P P performed the experiments. G A A and M F H analyzed the data. G A A, M F H, S R F, L M V, O P P and A B M contributed reagents/materials/analysis tools. $G A A$ and $A B M$ wrote the paper. $G A A$, M F H, S R F, L M V, R R, O P P and A B M corrected and read the last version.

\section{Acknowledgements}

The authors thank Enzo Cuba and Marcela Marquez for their technical support in the animal care and Dr Gladys Hermida for her support with histological techniques.

\section{References}

Abbott DH, Barnett DK, Bruns CM \& Dumesic DA 2005 Androgen excess fetal programming of female reproduction: a developmental aetiology for polycystic ovary syndrome? Human Reproduction Update 11 357-374. (doi:10.1093/humupd/dmi013)

Abbott DH, Bruns CR, Barnett DK, Dunaif A, Goodfriend TL, Dumesic DA \& Tarantal AF 2010 Experimentally induced gestational androgen excess disrupts glucoregulation in rhesus monkey dams and their female offspring. American Journal of Physiology: Endocrinology and Metabolism 299 E741-E751. (doi:10.1152/ajpendo.00058.2010)

Ables GP 2012 Update on Ppar. PPAR Research 20125. (doi:10.1155/2012/912351)

Amalfi S, Velez LM, Heber MF, Vighi S, Ferreira SR, Orozco AV, Pignataro O \& Motta AB 2012 Prenatal hyperandrogenization induces metabolic and endocrine alterations which depend on the levels of testosterone exposure. PLOS ONE 7 e37658. (doi:10.1371/journal. pone.0037658)

Baranova A, Tran TP, Birerdinc A \& Younossi ZM 2011 Systematic review: association of polycystic ovary syndrome with metabolic syndrome and non-alcoholic fatty liver disease. Alimentary Pharmacology \& Therapeutics 33 801-814. (doi:10.1111/j.1365-2036.2011.04579.x)

Baranova A, Tran TP, Afendy A, Wang L, Shamsaddini A, Mehta R, Chandhoke V, Birerdinc A \& Younossi ZM 2013 Molecular signature of adipose tissue in patients with both non-alcoholic fatty liver disease (NAFLD) and polycystic ovarian syndrome (PCOS). Journal of Translational Medicine 11 133. (doi:10.1186/1479-5876-11-133)

Browning JD \& Horton JD 2004 Molecular mediators of hepatic steatosis and liver injury. Journal of Clinical Investigation 114 147-152. (doi:10.1172/JCI200422422)

Brumbaugh DE \& Friedman JE 2014 Developmental origins of nonalcoholic fatty liver disease. Pediatric Research 75 140-147. (doi:10.1038/pr.2013.193)
C 2016 Society for Endocrinology Printed in Great Britain
Published by Bioscientifica Ltd. 
Burgert TS, Taksali SE, Dziura J, Goodman TR, Yeckel CW, Papademetris X, Constable RT, Weiss R, Tamborlane WV, Savoye M, et al. 2006 Alanine aminotransferase levels and fatty liver in childhood obesity: associations with insulin resistance, adiponectin, and visceral fat. Journal of Clinical Endocrinology \& Metabolism 91 4287-4294. (doi:10.1210/jc.2006-1010)

Chow JD, Jones ME, Prelle K, Simpson ER \& Boon WC 2011 A selective estrogen receptor alpha agonist ameliorates hepatic steatosis in the male aromatase knockout mouse. Journal of Endocrinology $\mathbf{2 1 0}$ 323-334. (doi:10.1530/JOE-10-0462)

Day CP \& James OF 1998 Steatohepatitis: a tale of two "hits"? Gastroenterology 114 842-845. (doi:10.1016/S0016-5085(98)70599-2)

Demissie M, Lazic M, Foecking EM, Aird F, Dunaif A \& Levine JE 2008 Transient prenatal androgen exposure produces metabolic syndrome in adult female rats. American Journal of Physiology: Endocrinology and Metabolism 295 E262-E268. (doi:10.1152/ajpendo.90208.2008)

den Boer M, Voshol PJ, Kuipers F, Havekes LM \& Romijn JA 2004 Hepatic steatosis: a mediator of the metabolic syndrome. Lessons from animal models. Arteriosclerosis, Thrombosis, and Vascular Biology 24 644-649. (doi:10.1161/01.ATV.0000116217.57583.6e)

Estall JL, Kahn M, Cooper MP, Fisher FM, Wu MK, Laznik D, Qu L, Cohen DE, Shulman GI \& Spiegelman BM 2009 Sensitivity of lipid metabolism and insulin signaling to genetic alterations in hepatic peroxisome proliferator-activated receptor-gamma coactivator-1alpha expression. Diabetes 58 1499-1508. (doi:10.2337/db08-1571)

Fernandez-Marcos PJ \& Auwerx J 2011 Regulation of PGC-1alpha, a nodal regulator of mitochondrial biogenesis. American Journal of Clinical Nutrition 93 884S-890S. (doi:10.3945/ajcn.110.001917)

Foecking EM, McDevitt MA, Acosta-Martinez M, Horton TH \& Levine JE 2008 Neuroendocrine consequences of androgen excess in female rodents. Hormones and Behavior 53 673-692. (doi:10.1016/j. yhbeh.2007.12.013)

Franks S 1995 Polycystic ovary syndrome. New England Journal of Medicine 333 853-861. (doi:10.1056/NEJM199509283331307)

Franks S 2003 Assessment and management of anovulatory infertility in polycystic ovary syndrome. Endocrinology and Metabolism Clinics of North America 32 639-651. (doi:10.1016/S0889-8529(03)00044-6)

Franks S \& Berga SL 2012 Does PCOS have developmental origins? Fertility and Sterility 97 2-6. (doi:10.1016/j.fertnstert.2011.11.029)

Gambarin-Gelwan M, Kinkhabwala SV, Schiano TD, Bodian C, Yeh HC \& Futterweit W 2007 Prevalence of nonalcoholic fatty liver disease in women with polycystic ovary syndrome. Clinical Gastroenterology and Hepatology 5 496-501. (doi:10.1016/j.cgh.2006.10.010)

Gluckman PD \& Hanson MA 2004 Developmental origins of disease paradigm: a mechanistic and evolutionary perspective. Pediatric Research 56 311-317. (doi:10.1203/01.PDR.0000135998.08025.FB)

Heber MF, Ferreira SR, Velez LM \& Motta AB 2013 Prenatal hyperandrogenism and lipid profile during different age stages: an experimental study. Fertility and Sterility 99 551-557. (doi:10.1016/j. fertnstert.2012.10.017)

Henkel J, Frede K, Schanze N, Vogel H, Schurmann A, Spruss A, Bergheim I \& Puschel GP 2012 Stimulation of fat accumulation in hepatocytes by PGE(2)-dependent repression of hepatic lipolysis, beta-oxidation and VLDL-synthesis. Laboratory Investigation 92 1597-1606. (doi:10.1038/labinvest.2012.128)

Hogg K, Wood C, McNeilly AS \& Duncan WC 2011 The in utero programming effect of increased maternal androgens and a direct fetal intervention on liver and metabolic function in adult sheep. PLOS ONE 6 e24877. (doi:10.1371/journal.pone.0024877)

Hsieh PS, Jin JS, Chiang CF, Chan PC, Chen CH \& Shih KC 2009 COX2-mediated inflammation in fat is crucial for obesity-linked insulin resistance and fatty liver. Obesity 17 1150-1157. (doi:10.1038/ oby.2008.674)

Ii H, Yokoyama N, Yoshida S, Tsutsumi K, Hatakeyama S, Sato T, Ishihara K \& Akiba S 2009 Alleviation of high-fat diet-induced fatty liver damage in group IVA phospholipase A2-knockout mice. PLoS ONE 4 e8089. (doi:10.1371/journal.pone.0008089)
Jang H, Bhasin S, Guarneri T, Serra C, Schneider M, Lee MJ, Guo W, Fried SK, Pencina K \& Jasuja R 2015 The effects of a single developmentally entrained pulse of testosterone in female neonatal mice on reproductive and metabolic functions in adult life. Endocrinology 156 3737-3746. (doi:10.1210/EN.2015-1117)

Jonard S \& Dewailly D 2004 The follicular excess in polycystic ovaries, due to intra-ovarian hyperandrogenism, may be the main culprit for the follicular arrest. Human Reproduction Update 10 107-117. (doi:10.1093/humupd/dmh010)

Jones H, Sprung VS, Pugh CJ, Daousi C, Irwin A, Aziz N, Adams VL, Thomas EL, Bell JD, Kemp GJ, et al. 2012 Polycystic ovary syndrome with hyperandrogenism is characterized by an increased risk of hepatic steatosis compared to nonhyperandrogenic PCOS phenotypes and healthy controls, independent of obesity and insulin resistance. Journal of Clinical Endocrinology \& Metabolism 97 3709-3716. (doi:10.1210/jc.2012-1382)

Karim BO, Landolfi JA, Christian A, Ricart-Arbona R, Qiu W, McAlonis M, Eyabi PO, Khan KA, Dicello JF, Mann JF, et al. 2003 Estrous cycle and ovarian changes in a rat mammary carcinogenesis model after irradiation, tamoxifen chemoprevention, and aging. Comparative Medicine 53 532-538.

Kawano Y \& Cohen DE 2013 Mechanisms of hepatic triglyceride accumulation in non-alcoholic fatty liver disease. Journal of Gastroenterol 48 434-441. (doi:10.1007/s00535-013-0758-5)

Kerner A, Avizohar O, Sella R, Bartha P, Zinder O, Markiewicz W, Levy Y, Brook GJ \& Aronson D 2005 Association between elevated liver enzymes and C-reactive protein: possible hepatic contribution to systemic inflammation in the metabolic syndrome. Arteriosclerosis, Thrombosis, and Vascular Biology 25 193-197. (doi:10.1161/01. ATV.0000148324.63685.6a)

Kim WR, Flamm SL, Di Bisceglie AM, Bodenheimer HC \& Public Policy Committee of the American Association for the Study of Liver D 2008 Serum activity of alanine aminotransferase (ALT) as an indicator of health and disease. Hepatology 47 1363-1370. (doi:10.1002/hep.22109)

Lee JH, Friso S \& Choi SW 2014 Epigenetic mechanisms underlying the link between non-alcoholic fatty liver diseases and nutrition Nutrients 6 3303-3325. (doi:10.3390/nu6083303)

Liang H \& Ward WF 2006 PGC-1alpha: a key regulator of energy metabolism. Advances in Physiology Education 30 145-151. (doi:10.1152/advan.00052.2006)

Lin Z, Cai F, Lin N, Ye J, Zheng Q \& Ding G 2014 Effects of glutamine on oxidative stress and nuclear factor-kappaB expression in the livers of rats with nonalcoholic fatty liver disease. Experimental and Therapeutic Medicine 7 365-370. (doi:L10.3892/etm.2013.1434)

Madan K, Bhardwaj P, Thareja S, Gupta SD \& Saraya A 2006 Oxidant stress and antioxidant status among patients with nonalcoholic fatty liver disease (NAFLD). Journal of Clinical Gastroenterology 40 930-935. (doi:10.1097/01.mcg.0000212608.59090.08)

Manikkam M, Steckler TL, Welch KB, Inskeep EK \& Padmanabhan V 2006 Fetal programming: prenatal testosterone treatment leads to follicular persistence/luteal defects; partial restoration of ovarian function by cyclic progesterone treatment. Endocrinology 147 1997-2007. (doi:10.1210/en.2005-1338)

Mao J, DeMayo FJ, Li H, Abu-Elheiga L, Gu Z, Shaikenov TE, Kordari P, Chirala SS, Heird WC \& Wakil SJ 2006 Liver-specific deletion of acetyl-CoA carboxylase 1 reduces hepatic triglyceride accumulation without affecting glucose homeostasis. PNAS 103 8552-8557. (doi:10.1073/pnas.0603115103)

Michaliszyn SF, Lee S, Tfayli H \& Arslanian S 2013 Polycystic ovary syndrome and nonalcoholic fatty liver in obese adolescents: association with metabolic risk profile. Fertility and Sterility $\mathbf{1 0 0}$ 1745-1751. (doi:10.1016/j.fertnstert.2013.08.015)

Motta AB, Estevez A \& de Gimeno MF 1999 The involvement of nitric oxide in corpus luteum regression in the rat: feedback mechanism between prostaglandin F(2alpha) and nitric oxide. Molecular Human Reproduction 5 1011-1016. (doi:10.1093/molehr/5.11.1011) 
Pan M, Cederbaum AI, Zhang YL, Ginsberg HN, Williams KJ \& Fisher EA 2004 Lipid peroxidation and oxidant stress regulate hepatic apolipoprotein B degradation and VLDL production. Journal of Clinical Investigation 113 1277-1287. (doi:10.1172/JCI19197)

Park JH, Kim SH, Park S \& Park MJ 2014 Alanine aminotransferase and metabolic syndrome in adolescents: the Korean National Health and Nutrition Examination Survey Study. Pediatric Obesity 9 411-418. (doi:10.1111/j.2047-6310.2013.00199.x)

Paschos P \& Paletas K 2009 Non alcoholic fatty liver disease and metabolic syndrome. Hippokratia 13 9-19.

Regueira E, Davila C \& Hermida GN 2016 Morphological changes in skin glands during development in Rhinella Arenarum (Anura: Bufonidae). Anatomical Record 299 141-156. (doi:10.1002/ar.23284)

Rosenfield RL 2007 Does a primary acceleration of LH pulse frequency underlie an association between central precocious puberty and polycystic ovary syndrome? Commentary on Escobar ME et al. Acceleration of LH pulse frequency in adolescent girls with a history of central precocious puberty with versus without hyperandrogenism (Horm Res 2007;68: 278-285). Hormone Research 68 286-287. (doi:10.1159/000104178)

Savage DB, Choi CS, Samuel VT, Liu ZX, Zhang D, Wang A, Zhang XM, Cline GW, Yu XX, Geisler JG, et al. 2006 Reversal of diet-induced hepatic steatosis and hepatic insulin resistance by antisense oligonucleotide inhibitors of acetyl-CoA carboxylases 1 and 2. Journal of Clinical Investigation 116 817-824. (doi:10.1172/JCI27300)

Schwimmer JB, Khorram O, Chiu V \& Schwimmer WB 2005 Abnormal aminotransferase activity in women with polycystic ovary syndrome. Fertility and Sterility $\mathbf{8 3}$ 494-497. (doi:10.1016/j.fertnstert.2004.08.020)

Souza-Mello V 2015 Peroxisome proliferator-activated receptors as targets to treat non-alcoholic fatty liver disease. World Journal of Hepatology 7 1012-1019. (doi:10.4254/wjh.v7.i8.1012)

Strable MS \& Ntambi JM 2010 Genetic control of de novo lipogenesis: role in diet-induced obesity. Critical Reviews in Biochemistry and Molecular Biology 45 199-214. (doi:10.3109/10409231003667500)
Vassilatou E 2014 Nonalcoholic fatty liver disease and polycystic ovary syndrome. World Journal of Gastroenterology 20 8351-8363. (doi:10.3748/wjg.v20.i26.8351)

Vassilatou E, Lafoyianni S, Vryonidou A, Ioannidis D, Kosma L, Katsoulis K, Papavassiliou E \& Tzavara I 2010 Increased androgen bioavailability is associated with non-alcoholic fatty liver disease in women with polycystic ovary syndrome. Human Reproduction $\mathbf{2 5}$ 212-220. (doi:10.1093/humrep/dep380)

Wolf CJ, Hotchkiss A, Ostby JS, LeBlanc GA \& Gray LE Jr 2002 Effects of prenatal testosterone propionate on the sexual development of male and female rats: a dose-response study. Toxicological Sciences 65 71-86. (doi:10.1093/toxsci/65.1.71)

Woodruff TK, Lyon RJ, Hansen SE, Rice GC \& Mather JP 1990 Inhibin and activin locally regulate rat ovarian folliculogenesis. Endocrinology 127 3196-3205. (doi:10.1210/endo-127-6-3196)

Yamada J, Tomiyama H, Yambe M, Koji Y, Motobe K, Shiina K, Yamamoto Y \& Yamashina A 2006 Elevated serum levels of alanine aminotransferase and gamma glutamyltransferase are markers of inflammation and oxidative stress independent of the metabolic syndrome. Atherosclerosis 189 198-205. (doi:10.1016/j. atherosclerosis.2005.11.036)

Yan X, Dai X, Wang J, Zhao N, Cui Y \& Liu J 2013 Prenatal androgen excess programs metabolic derangements in pubertal female rats. Journal of Endocrinology 217 119-129. (doi:10.1530/JOE-12-0577)

Yasui K, Hashimoto E, Tokushige K, Koike K, Shima T, Kanbara Y, Saibara T, Uto H, Takami S, Kawanaka M, et al. 2012 Clinical and pathological progression of non-alcoholic steatohepatitis to hepatocellular carcinoma. Hepatology Research 42 767-773. (doi:10.1111/j.1872-034x.2012.00986.x)

Yu J, Ip E, Dela Pena A, Hou JY, Sesha J, Pera N, Hall P, Kirsch R, Leclercq I \& Farrell GC 2006 COX-2 induction in mice with experimental nutritional steatohepatitis: role as pro-inflammatory mediator. Hepatology 43 826-836. (doi:10.1002/hep.21108)

Received in final form 9 May 2016

Accepted 13 May 2016

Accepted Preprint published online 13 May 2016
(C) 2016 Society for Endocrinology Printed in Great Britain 